\title{
O PROBLEMA DA INTENCIONALIDADE NA FÓRMULA “COMO ALGUÉM SE TORNA $O$ QUE SE É” DE NIETZSCHE
}

\author{
Jorge Luiz Viesenteiner \\ Pontifícia Universidade Católica do Paraná
}

\begin{abstract}
This paper aims to analyze the question of intentionality in the formula "How one becomes what one is," recorded by Nietzsche as subtitle to Ecce homo. The intentionality's problem emerges, first, from a phrase of Nietzsche's own book which reads: "That one becomes what one is presupposes that not even remotely suspects what one is"; and on the other hand, the hypothesis according to which 'become what one is' occurs only through the experiences (Erlebnisse), understood as pathos and therefore as a counter-concept of intentionality. The concepts of fate and fluidity are the two hypotheses that will be analyzed in order to distance ourselves from the problem of intentionality.
\end{abstract}

Key-words: Intentionality, Erlebnis, pathos, fate, fluidity.

Resumo: 0 objetivo deste artigo é analisar a questão da intencionalidade na fórmula "Como alguém se torna o que se é", registrada por Nietzsche como subtítulo a Ecce homo. 0 problema da intencionalidade emerge, por um lado, a partir de uma frase do próprio livro de Nietzsche que reza: "Que alguém se torne o que é pressupõe que não suspeite sequer remotamente o que é"; e, por outro lado, da hipótese segundo a qual 'tornar-se o que se é' ocorre unicamente através das vivências (Erlebnisse), compreendida como pathos e, portanto, como um contra-conceito à intencionalidade. Os conceitos de destino e fluidez serão as duas hipóteses que serão analisadas, a fim de nos distanciarmos do problema da intencionalidade.

Palavras-chave: Intencionalidade, Erlebnis, pathos, destino, fluidez.

\section{Introdução}

"Como alguém se torna o que se é" é o subtítulo do Ecce homo de Nietzsche e, além disso, uma fórmula que carrega consigo uma dimensão 
muito mais prática do que teórica, ou antes, uma práxis sem teoria. Nietzsche escreve no Ecce homo uma frase decisiva ao nosso texto e é a partir dela que formularemos nossas principais questões. A frase reza: "Que alguém se torne o que é pressupõe que não suspeite sequer remotamente $o$ que é” ${ }^{1}$. A frase registra um radical distanciamento de Nietzsche, por um lado, da tradição socrática do 'conhece-te a ti mesmo' e seus desdobramentos e, por outro lado, da tradição da intencionalidade, segundo a qual o homem é capaz de desdobrar suas ações no mundo através de uma formulação teóricointencional.

Segundo a frase registrada no Ecce homo, porém, Nietzsche desloca o horizonte epistemológico do 'tornar-se o que se é, para localizá-lo simplesmente na vida, em uma vida singular através das nossas vivências. Neste caso, não há modelos, codificações, elementos religiosos, conceituais ou morais que enquadre este 'tornar-se...', sobretudo porque à tarefa de 'tornar-se o que se é', exige-se precisamente a suspensão de quaisquer anteparos entre o homem e a vida e, principalmente, a supressão da compreensibilidade estritamente conceitual da existência ${ }^{2}$, incluindo-se aí a suspensão da própria intencionalidade. $\mathrm{O}$ pressuposto de não se saber " $O$ que" se é, para só então se "tornar", significa dizer que Nietzsche se distancia de qualquer formulação intencional na trajetória de 'tornar-se o que se é.' A intencionalidade já inclui uma compreensão conceitual da existência, pois tão logo sistematizamos nossas vivências, podemos então nos tornar uma ou outra coisa que já teria sido, antecipadamente, intencionada.

O problema se intensifica, além disso, tão logo assumimos a premissa segundo a qual não temos outra coisa em mãos na tarefa de 'tornar-se o que se é', a não ser nossa própria 'vivência' (Erlebnis). Substantivado a partir do verbo erleben, Erlebnis significa "estar ainda presente na vida quando algo

\footnotetext{
${ }_{1}^{1}$ NIETZSCHE, F. Ecce Homo, "Por que sou tão inteligente", §9. Doravante, EH.

2 Cf. NIETZSCHE, F. A Gaia Ciência, §370. Nietzsche se distancia da tradição socrático-platônico-cristã, na medida em que cria uma espécie de heurística da necessidade, ou seja, não por motivos ou fundamentos, mas pelas necessidades que causaram e coagiram alguma coisa. No aforismo, por exemplo, ele se refere a duas formas de sofredores, segundo suas necessidades de vida: os que sofrem por abundância e por empobrecimento de vida. São estes últimos que precisam planejar e interpretar teoricamente a vida e, portanto, constroem pontes morais, conceituais, religiosas, etc., entre ele e sua existência. Os que sofrem por abundância de vida, porém, são os homens de ação, aqueles que, na tarefa de 'tornar-se o que se é', possuem uma prática sem teoria, sem necessitarem incondicionalmente de um acesso conceitual e intencional à vida. Doravante GC.
} 
acontece" 3 . Assim, uma vivência tem o caráter de ligação imediata com a vida (Unmittelbarkeit), de modo que não se vivencia algo através do legado de uma tradição e nem através de algo de que "se ouviu falar", mas sim Erlebnis "é sempre vivenciada por um Si (Selbst)" efetivamente, "cujo conteúdo não se deve a nenhuma construção"4. Tal imediatez do homem com a vida em uma vivência, porém, significa que o homem nunca possui consciência daquilo que vivencia, no instante mesmo em que está vivenciando, de modo que o conteúdo de uma vivência não se deixa instrumentalizar racionalmente, estando ele, portanto, inteiramente oculto ao homem ${ }^{5}$. Só depois é possível sistematizar racional e conceitualmente aquilo que se vivenciou, conferindose inclusive um conceito ao que foi vivenciado. Estar imediatamente na vida quando algo acontece é, pois, estar patheticamente na vida e, neste caso, a noção de Erlebnis também precisa ser vinculada a pathos: "pathos não significa apenas 'paixão', 'afeto' e 'desejo', mas no grego ele está tanto para 'Erlebnis' como também para 'destino"”. N'A Gaia Ciência, por exemplo, Nietzsche escreve que não "nos tornamos conscientes do verdadeiro pathos de cada período da vida enquanto nele estamos...”.

Como pathos, vivência é um contra-conceito da razão, de modo que não pode ser compreendido tal como compreendemos um conceito, ou seja, fixo e racionalmente determinável. Tão logo conceitualizamos uma vivência, então ela deixa de ser pathos e se torna conceito, derivando-se daí o fato de que Erlebnis é uma noção conceitualmente incompreensível. Na medida em que nunca estamos conscientes do pathos próprio da vida e, neste caso, impossibilitados de determinar racionalmente o conteúdo efetivo daquilo que estamos vivenciando, então, suspende-se também qualquer possibilidade de intencionalidade em uma vivência, tornando-a inteiramente incomensurável. Nosso problema, pois, equaciona-se através dessas duas premissas: por um lado, segundo a proposição nietzscheana, 'tornar-se o que

\footnotetext{
${ }^{3}$ Cramer, K. "Erleben, Erlebnis". In Ritter, Joachim (Hrsg.) Historisches Wörterbuch der Philosophie. Band 2: D-F. Basel/Stuttgart: Schwabe \& Co. Verlag, 1972, p. 703. Salvo indicações contrárias, as traduções do alemão e do inglês são de minha própria autoria.

4 Idem. Cf. também GADAmER, H-G. Wahrheit und Methode: Grundzüge einer philosophischen Hermeneutik. Tübingen: J.C.B. Mohr, 1990. p. 66.

${ }^{5}$ Cf. VISSER, G. Erlebnisdruck: Philosophie und Kunst im Bereich eines Übergangs und Untergangs. Würzburg: Königshausen \& Neumann, 2005, p. 62: "Esse é o motivo para diferenciar um terceiro tema: a impossibilidade de esgotar o conteúdo da vivência através de meios racionais."

${ }^{6}$ Cf. GerhardT, V. Pathos und Distanz. Stuttgart: Reclam, 1988. p. 8.

7 GC $\S 317$.
} 
se é' não pressupõe que saibamos de antemão "o que” se é, suspendendo-se um saber conceitual e intencional em querer se tornar algo que foi previamente conceitualizado; e, por outro lado, 'tornar-se o que se é' ocorre unicamente na vida, na Erlebnis e, enquanto vivenciamos, nunca estamos conscientes do conteúdo do que é vivenciado e, portanto, se não há consciência, não há intencionalidade. ${ }^{8}$

Assim, pois, é que emerge o problema da intencionalidade na tarefa de 'tornar-se o que se é', pois trata-se de um processo que se desdobra sob condições individuais de vida, sem universalizá-lo em um modelo unívoco e nem orientado por uma compreensibilidade conceitual da existência, pois como foi escrito, na tarefa de 'tornar-se...' não se pressupõe que já saibamos de antemão "o que" somos. Não há qualquer ordenação moral e intencional no mundo e nem é possível determinar qual vivência em específico alguém precisa atravessar, à tarefa de 'tornar-se o que se é'. Todos os meios através dos quais o homem "se torna" são radicalmente imorais. Não há ordenações e nem planejamentos; e nas ações que realizamos na tarefa de 'tornar-se o que se é' não há, enfim, intencionalidade. ${ }^{9}$

A partir daí, a tarefa de 'tornar-se o que se é, patheticamente considerada, tem dois indicativos de explicação: por um lado, em que medida Nietzsche assume essa tarefa como um destino e, por outro lado, como ele insere essa fórmula sob o signo do pensamento da fluidez. Do ponto de vista metodológico, dividiremos nosso texto a partir de uma sistemática interpretação da frase "wie man wird, was man ist"10, sob a perspectiva do

\footnotetext{
8 Cf. 0 apontamento póstumo da primavera de 1888, vol. 13, 15[90], intitulado "O fenomenalismo do 'mundo interior'", In NIETZSCHE, F. Kritische Studienausgabe in 15 Bänden. Hrsg. Giorgio Colli und Mazzino Montinari. Berlin/New York: DTV \& Walter de Gruyter, 1980. Doravante KSA, no do volume, nº do apontamento.

${ }^{9}$ Cf. NIETZSCHE, F. Além do bem e do mal, § 32. Doravante ABM.

$10 \mathrm{Cf}$. a minuciosa interpretação de SCHANK, G. "Dionysos gegen den Gekreuzigten: eine philologische und philosophische Studie zu Nietzsches 'Ecce homo'". Bern/Berlin: Europäischer Verlag der Wissenschaften, 1993. Segundo o autor, "as explicações de Nietzsche sobre seu método [em Ecce homo - JLV] se deixam explicar com duas palavras-chave: a recusa da 'argumentatio ad personam', bem como o procedimento 'semiótico'" (p. 86). Neste aspecto, Nietzsche nunca ataca diretamente às pessoas (EH, Por que sou tão sábio, §7) e, quando se refere a elas o faz as empregando como um 'semiótica' para expressar seus próprios pensamentos (EH, As extemporâneas, §3). Schank também se refere às três partículas que compõem a fórmula: "quem fala, como é tratado, e sobre o que é isso que se é falado, isto é, do que se trata o diálogo" (p. 87). Apesar da nossa metodologia também focalizar as mesmas partículas, procederemos de modo sistemático às palavras a partir do contexto do nosso texto, bem como do contexto do emprego de tais signos no conjunto dos escritos de Nietzsche.
} 
quem (man), como (wie... wird) e o quê (was man ist). Separaremos as palavras da fórmula para dar sintonia com a seqüência do nosso argumento, iniciando pelo 'o que se é' (was man ist).

\section{Intencionalidade e 'tornar-se o que se é'}

[1] Was man ist. O subtítulo de Ecce homo é emprestado por Nietzsche das Odes Píticas de Píndaro, em especial a segunda das "Odes" dirigidas a Hieron que reza "Genoi' hoios essi mathon"11. No entanto, Nietzsche transcreve o ode de Píndaro erroneamente, erro talvez proposital, pois ele simplesmente não inclui a palavra mathon, que por sua vez, alude à medida, ao conhecimento ou ao aprendizado no contexto da frase de Píndaro. De difícil tradução, a frase possui inúmeras variações quando a lemos incluindo a palavra mathon: "Tendo aprendido o que você é, torna-te tal como você é"; "Sê fiel a ti mesmo agora que aprendestes que espécie de homem te apetece", ou ainda simplesmente "Seja o que você conhece que você e'" 12 . A palavra mathon modifica por completo o contexto da frase, na medida em que ela implica, primeiramente, um conhecimento que o homem tem sobre o que é, para só então, tornar-se aquilo que ele aprendeu que é. ${ }^{13}$

Curiosamente, a palavra que pertence à expressão de Píndaro nunca é registra por Nietzsche. Assim procedendo, Nietzsche marca um distanciamento em relação à tradição metafísica, segundo a qual todo homem pode bem compreender algo, inclusive o que ele é, se assim quiser, se for conceitualmente sistematizado e se for comunicado através de uma

\footnotetext{
11 Pítica 72, genoi' hoios essi mathon. Sobre o tema cf. NeHAMAS, A. Nietzsche: la vida como literatura. México: Fondo de Cultura Econômica, 2002, especialmente a nota 2 do capítulo seis, intitulado "como se chega a ser o que se é".

12 Sobre essa discussão, cf. BABICH, B. "Nietzsche's Imperative as a Friend's Encomium: on becoming the one you are, ethics, and blessing". In Nietzsche-Studien 32(2003), p. 29-58: "Embora o verso de Píndaro seja de difícil tradução, há uma falta de padrão e padronização nas traduções". As traduções são: "Become such as you are, having learned what that is"; "Be true to thyself now that thou hast learnt what manner of man thou art"; "Be what you know you are" (p. 31).

13 A primeira ocorrência de alusão à frase de Píndaro ocorre na terceira extemporânea sobre Schopenhauer: "seja você mesmo!" (sei du selbst!) (Co.Ext. III, SE. In: KSA 1, p. 337). A expressão recorrente depois disso é "Torna-te o que você é", cuja primeira ocorrência é de um fragmento do outono/dezembro de 1876 (KSA 8, 19[40]). As variações da expressão são muitas depois disso. A alusão ainda aparece em GC §270; KSA 9, 11[297] e Assim falou Zaratustra, "O sacrifício do mel". (Trad. Mario da Silva). Rio de Janeiro: Bertrand Brasil, 1998. Doravante Za. A fórmula clássica "como alguém se torna o que é" aparece somente no Ecce homo.
} 
linguagem em comum $^{14}$. Por um lado, este distanciamento se insere ainda naquilo que denominamos como projeto de inversão da compreensibilidade $^{15}$ e, por outro, implica em suspender precisamente a intencionalidade.

Ora, somente depois que alguém "souber" o que é, então, pode se tornar aquilo que conheceu de si mesmo. Dessa perspectiva, "tornar-se" se desdobra através de um processo intencional, na medida em que se configura como execução prática, oriunda do saber teórico sobre si mesmo. Se sou "isso", então também devo me "tornar isso". No entanto, Nietzsche opera uma enorme variação semântica ao dizer que se alguém quer se tornar o que é, deve também pressupor "que não suspeite sequer remotamente o que é". 'Tornar-se o que é' não implica a conceitualização teórica da noção homem, para só depois tornar-se isso que alguém conheceu de si mesmo e conceitualizou. Neste caso, embora evoque a expressão pítica, trata-se de uma oposição direta e sistemática a Píndaro, na medida em que seu Ode significaria a própria vulgarização, estreitamento e mediocrização do conceito de homem: uma generalização da finalidade do homem através do conceito.

Há uma insistência aqui na impossibilidade da determinação conceitual do que é o homem para, depois, torná-lo intencionalmente aquilo

${ }^{14} \mathrm{Cf}$. ABM $\S 268$.

${ }_{15}$ Trata-se de um questionamento que Nietzsche faz, segundo o qual qualquer um poderia compreender bem a um outro se assim o quisesse e se este outro se fizesse suficientemente claro. 0 discurso filosófico se caracteriza precisamente por essa pretensão de meta-compreensibilidade ou ainda de uma compreensão supra-individual, na medida em que uma doutrina ou sistema pressupõe que alguém pode perfeitamente ser compreendido universal e univocamente, revelando-se no fundo como um gigantesco preconceito, bem como uma a-temporalização do pensamento. À base dessa exigência por compreensão universal e unívoca está a des-individualização do próprio homem e das suas condições peculiares de vida, quer dizer, a exigência por ter algo "em comum" (gemein) (ABM §268) com as coisas e com os outros. Porém, ter algo 'em comum' e ser compreendido é, segundo Nietzsche, absolutamente "ofensivo" (KSA 12, 1[182] p. 50). Com base nisto, o projeto crítico de inversão da compreensibilidade se estrutura através de três hipóteses centrais: a) a temporalização do pensamento e, dessa forma, remontar às condições individuais do emprego de um conceito, um signo, uma ação, etc.; b) tal reconquista da individualidade do pensamento implica em compreendê-lo de maneira fluida, na medida em que tão logo se alterem as condições individuais do emprego de um conceito, altera-se também seu sentido. (GM II, §12). A fluidez de um pensamento significa que o sentido de algo pode continuamente ser deslocado, aumentando ou diminuindo as margens de atuação de tal conceito; c) Nietzsche não parte mais da vontade incondicional de ser compreendido e, sobretudo, universal e univocamente compreendido, mas ao contrário, quer resgatar a individualidade do seu pensamento e, para isso, parte da hipótese de que "não queremos apenas ser compreendidos ao escrever, mas igualmente não ser compreendidos" (GC §381). 
que mensurou a determinação racional. Em um fragmento do outono de 1880, Nietzsche se distancia dessa hipótese ao escrever:

Tão logo queiramos determinar a finalidade do homem, antecipamos um conceito de homem. Mas dos indivíduos conhecidos de até então, tal conceito só pode ser conquistado de tal modo que se retira toda individualidade - logo, estabelecer a finalidade do homem significaria coibir os indivíduos em sua individualidade, ou seja, torná-los universais/comuns (allgemein). ${ }^{16}$

O homem não é determinável e nem sequer comensurável a ponto de ser reduzido à universalidade do conceito. Um conceito de homem exprime uma doutrina que comunica e é univocamente compreendida por todos. $\mathrm{O}$ anúncio de Zaratustra, porém, comunica que "o homem é algo que deve ser superado"17, e superados devem também ser todos os conceitos que pretendam a compreensão unívoca do que é o homem. A partícula "o que se é” da fórmula 'tornar-se o que se é' permanece incomensurável, de modo que seu conteúdo está conceitualmente obstruído para nós. Essa era, porém, a mesma hipótese que já afirmamos inicialmente sobre a noção de vivência ${ }^{18}$. Como pathos, tornar-se o que se é se desdobra unicamente na vida e através das próprias vivências, mas não podemos determinar, de antemão, $o$ que é o homem e nem sequer qual vivência ele deve experimentar. ${ }^{19}$

Nietzsche situa a fórmula 'tornar-se o que se é, porém, na perspectiva da necessidade e do destino, que por sua vez, não seria autorizado para todos

\footnotetext{
${ }^{16}$ Apontamento póstumo do outono de 1880, in: KSA 9, 6[158] p. 237.

17 Za, Prólogo, §3.

${ }^{18}$ Nietzsche já havia se deparado com o problema da incomensurabilidade intencional da vida no verão 1875, a propósito da sua leitura da obra de Eugen Dühring intitulada Der Werth des Lebens (cf. KSA 8, 9[1]). Essa mesma hipótese, porém, volta em seus escritos formulada como tese canônica no Crepúsculo dos ídolos, segundo a qual "o valor da vida não pode ser estimado". Cf. NiETzSCHE, F. Crepúsculo dos Ídolos, "O problema de Sócrates", §2. Doravante Cl.

19 Cf. VISSER, Gerard. "Nietzsches Übermensch: die Notwendigkeit einer Neubesinnung auf die Frage nach dem Menschen". In Nietzsche-Studien 28(1999), p. 100-124. Aqui na p. 107: "O fim do homem é para Nietzsche o fim do conceito 'homem' e o início de uma espécie mais elevada, cujas condições de surgimento não são mais humanamente universais, mas sim individuais". No diálogo de Zaratustra com a vida, em $O$ canto de dança, a própria vida se revela imperscrutável e, portanto, não se oferece à comensurabilidade, ou seja, não é possível determinar o valor da vida. Cf. ainda NIETZSCHE, F. Aurora, $\S 119$. Doravante A; e Cl, "Moral como antinatureza", §5; por fim, confira ainda o apontamento do início de 1880, in: KSA 9, 1[38].
} 
em comum. Em 1876 ele escreveu: “'Torna-te quem tu és': este é um grito que sempre é permitido apenas a poucos homens, mas que é supérfluo só para um mínimo dentre estes poucos" ${ }^{20}$. A mesma tarefa para poucos de 'tornar-se o que se é' é repetida igualmente em Ecce homo, mas agora sob o peso e a fatalidade do destino: "Pois admitindo que a tarefa, a destinação, o destino da tarefa ultrapasse em muito a medida ordinária, nenhum perigo haveria maior do que perceber-se com essa tarefa"21. No Ecce homo, Nietzsche se exprime também como um destino quando escreve: "pois eu carrego nos ombros o destino da humanidade"22; além disso, não apenas afirma ser "o homem da fatalidade", mas também pergunta pelos motivos que o tornou um destino, registrado sob o título "Por que" sou um destino ${ }^{23}$. A personificação do destino de uma tal tarefa, além disso, se faz homem na figura do seu Zaratustra: "Querem uma fórmula para um destino assim, que se fez homem? - Ela se encontra no meu Zaratustra" ${ }^{24}$. Zaratustra se torna o mestre do eterno retorno e, desde muito cedo, já havia reconhecido tal destino. E se Nietzsche escreveu que 'conhece seu destino', também deixou que Zaratustra igualmente o reconhecesse: "Reconheço meu destino - disse ele, por fim, com tristeza. - Pois muito bem! Estou pronto. Começou, agora, a minha última solidão". ${ }^{25}$

Destino é um contra-conceito da racionalidade e, simultaneamente, a suspensão da intencionalidade. O que se impõe com o peso da fatalidade não pode ser avaliado ou comensurado intencionalmente. Se é destino, não pode ser intencional. Por um lado, "destino é um conceito que fazemos a nós sobre um acontecimento que é imprevisível e inalterável, a fim de identificar o que não é, porém, identificável (e as vezes também personificar). $\mathrm{O}$ conceito sistematiza o que não é sistematizável e, na medida em que conceitualiza o que não é sistematizável, ele se torna um conceito

\footnotetext{
${ }^{20}$ Apontamento póstumo de outubro/dezembro de 1876, in: KSA 8, 19[40] p. 340.

${ }^{21} \mathrm{EH}$, "Por que sou tão inteligente", §9.

$22 \mathrm{EH}$, "O Caso Wagner", §4.

${ }^{23} \mathrm{EH}$, "Por que sou um destino", §1. Cf. também EH, "Crepúsculo dos Ídolos", §2: "Exatamente por isso sou também um destino". Nietzsche também reconhece, como destino, a tarefa de uma transvaloração dos valores, de modo a querer gravar "signo por signo em tábuas de bronze", a certeza de tal tarefa e "com a segurança própria de um destino" (EH, "Crepúsculo dos Ídolos", §3).

${ }^{24} \mathrm{EH}$, "Por que sou um destino", §2. Nietzsche escreve que Zaratustra é um 'dançarino', pois mesmo sendo "o espírito portador do mais pesado destino, de uma fatalidade de tarefa, pode no entanto ser 0 mais além e mais leve" (EH, "Assim falou Zaratustra", §6).
}

${ }^{25} \mathrm{Za}$, "O viandante", p. 162. 
paradoxal"26. Destino é um contra-conceito da razão na medida em que é compreendido também como um pathos, pois no grego, conforme nota acima, pathos também pode significar destino ${ }^{27}$. Para além de toda lógica, como pathos, o destino também não pode ser conceitualizado e, além disso, não pode ser compreendido como se compreende um conceito. Destino é o absolutamente outro da razão e precisamente aquilo que ela não controla: nele, as leis da lógica estão suspensas. Da mesma maneira, por outro lado, trata-se da suspensão da intencionalidade. Se o destino tenta sistematizar o que é imprevisível e inalterável, ele se impõe como um pathos independentemente da intencionalidade de alguém. Mesmo a tentativa de alterar ou prever intencionalmente o destino já faz parte da economia geral daquilo que tinha que acontecer. Sob o peso do destino, a intencionalidade se torna um conceito dispensável, e se o destino se faz homem através de Zaratustra, ele o recebe inclusive sob a forma de "revelação", absolutamente involuntário e sem que ele tenha tido qualquer outra "opção". ${ }^{28}$

As vivências não são previamente intencionadas e nem têm seu conteúdo determinado, mas surgem como "destinos e tremores". ${ }^{29}$ Tudo se impõe como "necessidade" 30 , "tudo se revela como algo que "tinha de acontecer" 31 . É dessa forma que a tarefa de 'tornar-se o que se é não é primeiramente planejada e nem desdobrada segundo uma intencionalidade, mas ela simplesmente se impõe, ou seja, como um pathos, como destino. Não há um substrato daquilo que o homem é, para depois realizá-lo em um vir-a-ser. Nietzsche escreve que não vivenciamos algo como um "querer vivenciar"32. Aliás, se há algum querer no processo de 'tornar-se o que se é, é unicamente querer o próprio destino sob a forma de afirmação. Essa é a

\footnotetext{
${ }^{26}$ Stegmaier, W. Schicksal Nietzsche? Zu Nietzsches Selbsteinschätzung als Schicksal der Philosophie und der Menschheit. (Ecce homo: Warum ich ein Schicksal bin, 1). In Nietzsche-Studien 37(2008) p. 62114. Aqui na p. 72.

${ }^{27}$ Cf. GeRHARDT, V. Pathos und Distanz, p. 8.

${ }^{28} \mathrm{EH}$, "Assim falou Zaratustra", §3: "Havendo o menor resquício de superstição dentro de si, dificilmente se saberia afastar a idéia de ser mera encarnação, mero porta-voz, mero medium de forças poderosíssimas. A noção de revelação, no sentido de que subitamente, com inefável certeza e sutileza, algo se torna visível (...). Ouve-se, não se procura; toma-se, não se pergunta quem dá; um pensamento reluz como relâmpago, com necessidade, sem hesitação na forma - jamais tive opção."

${ }^{29} \mathrm{~A}, \S 481$. Tradução modificada.

30 GC, §109 e NIETZSCHE, F. Humano, demasiado Humano, §107. Doravante HH.

${ }^{31} \mathrm{GC}, \S 277$. Cf. também BABICH, Babette. E. op. cit., p. 51.

${ }^{32} \mathrm{Cl}$, "Incursões de um extemporâneo", §7. Cf. também KSA 12, 9[110].
} 
única maneira que Zaratustra diz "querer" seu destino: "Mas assim quer a minha vontade criadora, o meu destino. Ou, para falar-vos mais honestamente: tal destino, justamente, - é o que quer a minha vontade"33. Aí não há intencionalidade, não há um querer diferente daquilo que se impõe, mas antes, há apenas afirmação desse pathos. Quando se quer inclusive aquilo que também 'não é querido', a própria vontade não se coloca mais em oposição ao destino ${ }^{34}$, por isso que Zaratustra é o único a poder redimir todo "foi assim" em um "assim eu o quis". ${ }^{35}$

O mais interessante, porém, é perceber que Nietzsche também se refere da mesma maneira no Ecce homo, dessa vez se referindo a si mesmo. Ele caracteriza sua maior sensatez, inclusive, como "tomar a si mesmo como um fado, não se querer 'diferente"' 36 . No Ecce homo, ao assumir a tarefa de 'tornar-se o que se é', Nietzsche não apenas diz que nunca teve desejo algum, mas, sobretudo, que nunca quis algo diferente daquilo que ele se tornou: "Não quero em absoluto que algo se torne diferente do que é; eu mesmo não quero tornar-me diferente. Mas assim vivi sempre. Não tive desejo algum"37. Em relação ao futuro, não há também nenhuma intencionalidade. No mesmo texto Nietzsche escreve: "Ainda neste momento olho para meu futuro - um vasto futuro - como para um mar liso: nenhum anseio o encrespa”. Querer o destino, pois, não é querer alterá-lo intencionalmente ou ainda instrumentalizar de tal modo o 'tornar-se', que alguém já poderá saber, de antemão, o que se tornará no futuro. Neste caso, o tornar-se 'o que se é' suspende a intencionalidade de querer ser isto ou aquilo, pois o 'tornar-se' se impõe como destino, patheticamente e sem escolhas; ou melhor, se há

\footnotetext{
${ }^{33} \mathrm{Za}$, "Nas ilhas bem-aventuradas", p. 101. Curioso lembrar que também o "indivíduo soberano" é capaz de prometer e manter a promessa inclusive "contra o destino" (GM II, §2). Além disso, homens que querem o próprio destino, podem também agir como um destino, pois "eles vêm como 0 destino, sem motivo, razão, consideração, pretexto" (GM II, §17). Sobre o tema agir como um destino, cf. ainda StEgmaIER, W. Schicksal Nietzsches?, p. 73.

${ }^{34}$ Essa é a perspectiva de Zaratustra em "Da bem-aventurança a contra-gosto". Querer inclusive o que não é querido é precisamente como Zaratustra se coloca diante do destino: "vitorioso e com passo firme, estava novamente em pé no seu destino". (p. 168s.).

${ }_{35} \mathrm{Za}$, "Da redenção", p. 151.

${ }^{36} \mathrm{EH}$, "Por que sou tão sábio", §6. Segundo BABICH, Babette E. op.cit., p. 44s., 'tornar-se o que se é' como um querer não ter sido diferente daquilo que se tornou é, simultaneamente, a forma suprema de reconciliação com o passado e, portanto, a maneira de se elevar a todo ressentimento.

${ }^{37} \mathrm{EH}$, "Por que sou tão inteligente", §9. Cf. ainda EH, "O caso Wagner", §4: "Nada desejo diferente, também para trás não. - Nada pude desejar diferente... Amor fati... Mesmo o cristianismo torna-se necessário".
} 
alguma opção, é precisamente não querer ter sido diferente daquilo que alguém se tornou ou se torna. ${ }^{38}$

Não nos é mais lícito, portanto, pressupor uma intencionalidade na tarefa de 'tornar-se o que se é'. Quando Nietzsche simplesmente não cita a palavra mathon do Ode de Píndaro, significa que ele se distancia da possibilidade de primeiro instrumentalizar racionalmente o que é o homem, para só então realizá-lo no vir-a-ser. É impressionante a peculiaridade de Nietzsche ao suprimir uma palavra tão decisiva a Píndaro, mas mais decisiva ainda à própria fórmula de Nietzsche. Situando-a como destino, ele suspende a intencionalidade, relegando o homem ao pathos próprio da vida, incomensurável e incompreensível. ' $O$ que' $\mathrm{o}$ homem 'se torna' não pressupõe mais nenhuma comensurabilidade de conceitos e nem uma intencionalidade naquilo que ele quer se tornar. Tudo se impõe, enfim, como pathos, um destino que é, no fundo, o "destino da tarefa" de 'tornar-se aquilo que se é'.

[2] man. A fórmula nietzscheana wie man wird, was man ist é comumente relacionada a uma espécie de autobiografia de Nietzsche. Em oposição a esta perspectiva, não consideramos que se trate de algo autobiográfico, mas antes, uma espécie de auto-genealogia, na medida em que as vivências (Erlebnisse) não são a confissão das memórias de um autor, mas sim as condições através das quais seus pensamentos emergiram e se desenvolveram ${ }^{39}$. A partícula 'man' da fórmula nietzscheana indica a escrita em $3^{\circ}$ pessoa do singular e, neste caso, uma escrita impessoal. Nietzsche não escreve 'como eu me tornei o que eu sou' (wie ich mich geworden bin, was ich bin); mais uma vez, ele se distancia criticamente da pessoalidade dos seus escritos, renuncia a dizer 'eu' e contar suas memórias, para conferir à escrita uma impessoalidade que corresponde precisamente à partícula alemã man.

É certo, de fato, que Ecce homo é a última tentativa de Nietzsche de conhecer melhor a si mesmo e, além disso, o texto é freqüentemente escrito em primeira pessoa. Produzido essencialmente entre 15 de outubro e 4 de novembro, e recebendo inúmeras revisões posteriores, Ecce homo pode sim

${ }^{38} \mathrm{Cf}$. BABICH, B. op.cit., p. 30: "Sua única tarefa seria assim: ser simplesmente o que você já é, o que você já se tornou."

${ }^{39}$ Sobre o tema cf. Stegmaier, W. "Nietzsches Kritik der Vernunft seines Lebens: Zur Deutung von 'Der Antichrist' und 'Ecce Homo'". In Nietzsche-Studien 21 (1992), p. 163-183. 
ser considerado o "ponto de culminância da obra de Nietzsche"40. No entanto, mais do que a narrativa de suas memórias, Nietzsche indica uma genealogia de seu pensamento, na medida em que os títulos dos capítulos correspondem a perguntas de caráter genealógico: "Por que sou tão sábio", "Por que sou tão inteligente", "Por que escrevo tão bons livros", seguindo-se uma análise de cada um de seus textos publicados com seus respectivos contextos e, por fim, "Por que sou um destino". Se há algo de biográfico em Ecce homo, é simplesmente porque o livro representa as condições de um "agradecido" 41 e, além disso, somente na medida em que ele opera uma genealogia do pensamento de Nietzsche. ${ }^{42}$

A partícula man não alude em específico a Nietzsche, indicando o que ele se tornou. Se a partícula é impessoal e indeterminada, indeterminado é também aquilo que o próprio homem é. Como pathos, Nietzsche não poderia ter dado uma definição de homem e nem sequer sistematizado conceitualmente o que ele se tornou, numa espécie de autobiografia. Mesmo o conceito de "além-do-homem" é contextualizado por Nietzsche também como uma semiótica, uma palavra e um símbolo ${ }^{43}$ e, enquanto tal, precisa ser compreendido não como um conceito, mas sob o signo da sua fluidez. Tratase de um conceito que vai para além da univocidade de todos os outros conceitos de homem, tornando-os paradoxais, a fim de abrir novas Spielräume de interpretações ${ }^{44}$. Daí o porquê Nietzsche não poderia, ao final,

\footnotetext{
40 Sobre a história do surgimento do Ecce homo, cf. MontINARI, M. "Ein neuer Abschnitt in Nietzsches Ecce homo". In Nietzsche-Studien 1(1972) p. 380-418, bem como KSA 14, p. 454-470. Sobre a hipótese de Ecce homo como ponto de culminância na filosofia de Nietzsche, cf. KORNBERGER, Martin. "Zur Genealogie des 'Ecce homo'". In Nietzsche-Studien 27(1998) p. 319-338, aqui citado na p. 325.

${ }^{41}$ Nietzsche escreveu na epígrafe de Ecce homo: "Como não deveria ser grato à minha vida inteira?". Em um fragmento póstumo contemporâneo à Ecce homo, KSA 13, 24[3] p. 362, Nietzsche ainda se refere à Ecce homo nos seguintes termos: "Ecce homo: anotações de alguém múltiplo". O aforismo imediatamente anterior a esse reza: "In media vita. Anotações de um agradecido".

${ }^{42}$ Sobre a hipótese do Ecce homo não como autobiografia, mas sim auto-genealogia, cf. BABICH, B., op. cit., p. 48, onde a autora se refere à "Auto-bibliografia"; SCHANK, G. op.cit., p. 78, principalmente onde 0 autor escreve que a "intenção principal de 'Ecce homo' " seria "alcançar uma melhor compreensão para seus escritos e teorias". Cf. ainda STEGMAIER, W. Schicksal Nietzsches?, p. 65s. e especialmente a nota 8 do texto. Por fim, na seção de contribuições à Ecce homo do periódico Nietzscheforschung, tanto Enrico Müller quanto Andreas Urs Sommer se referem igualmente ao texto como genealogia e não autobiografia. In: Nietzscheforschung 12(2005) p. 127-131, especialmente as páginas 128 e 130.

${ }^{43} \mathrm{Cf}$. KSA 12, 10[17].

${ }^{44} \mathrm{Cf}$. EH, "Por que escrevo tão bons livros", §1: "A palavra 'Übermensch', para designação de um tipo que vingou superiormente, em oposição a homens 'modernos', a homens 'bons', a cristãos e outros niilistas". Cf. ainda EH, "Por que sou um destino, §5; AC, §4 e VISSER, G. Nietzsches Übermensch, p.
} 
estabelecer precisamente um conceito para a fórmula 'tornar-se o que se é' e nem um conceito para si mesmo.

A fórmula possui uma partícula indeterminada porque o homem é o animal mais "indeterminado" 45 . Perguntar "o que eu sou, afinal" se torna absolutamente ingênuo, pois o homem é incomensurável e não é conceitualmente sistematizável, a não ser que seja compreendido como 'mera semiótica', e nada além. Ao contrário, o homem pode dar a si mesmo inúmeras "formas" ou ainda "a ausência de forma" 46 . Na medida em que Nietzsche se refere ao homem como "o animal ainda não determinado" 4 , resta a ele se distanciar de qualquer instrumentalização em um conceito específico, a fim de se situar na mais extrema "abertura"48. Não é possível operar nenhuma forma de determinação, pois toda determinação já representa a identificação com um conceito. Como "animal ainda não determinado", se o homem se tornou o que ele deve se tornar, então ele já não é mais o que corresponde propriamente a ele, ou seja, algo ainda não 'determinado' e que deve sempre 'se tornar'. Ao se tornar e, simultaneamente, identificar-se a um conceito, o homem já não mais 'se torna'. ${ }^{49}$

$\mathrm{Na}$ série de poemas publicados n'A Gaia Ciência intitulados "Brincadeira, astúcia e vingança", há um pequeno poema que Nietzsche nomeia como "Ecce homo". Ao empregar a metáfora do fogo, numa clara e direta alusão a Heráclito, Nietzsche insiste ali no caráter mutável e fluido do conceito homem, alguém que, na trajetória de 'tornar-se o que se é, "está ainda inesgotado para as grandes possibilidades" 50 . O poema diz: "Sim, eu sei de onde sou!/ Insaciável como o fogo/ Eu ardo e me consumo./ Tudo o que

100 e Stegmaier, W. "Anti-Lehren: Szene und Lehre in Nietzsches Also Sprach Zarathustra". In GERHARDT, V. (Hg.), Klassiker auslegen: Friedrich Nietzsche: Also Sprach Zarathustra, Berlin: Akademie Verlag, 2000, p. 211: "O pensamento do além-do-homem, ao contrário, seria 0 ultrapassamento do pensamento de homem para além de toda normatização."

$45 \mathrm{GM}$ III, $\S 13$.

${ }^{46}$ KSA 9, 6[147] p. 234.

${ }^{47}$ ABM, §62. Cf. também KSA 11, 25[428] e KSA 12, 2[13].

${ }^{48}$ C. VISSER, G. op. cit., p. 122: 'Ocorre na e com a questão, que precisamente o 'eu' não tem mais nenhum ponto de referência e mais nenhum lugar, mas se deixa significar com toda cautela como abertura." Cf. também StEInMAnN, M. Die Ethik Friedrich Nietzsches. (Monographien und Texte zur Nietzsche-Forschung). Berlin/New York: Walter de Gruyter, 2000, p. 187.

${ }^{49}$ Sobre o tema, cf. Tongeren, Paul v. Die Moral von Nietzsches Moralkritik: Studie zu "Jenseits von Gut und Böse". Bonn: Bouvier, 1989, p. 74-78, especialmente o sub-capítulo intitulado "O homem: 0 animal ainda não determinado".

${ }^{50} \mathrm{ABM}, \S 203$. 
toco vira flama/ E tudo o que deixo, carvão:/ Sou fogo, não há dúvida”. A melhor definição que se poderia dar ao homem, fazendo-o permanecer no seu caráter de abertura, é quando Nietzsche diz de si mesmo: "eu sou uma nuance" ${ }^{\text {. }}$. Uma nuance é algo que sempre se desloca do seu sentido originário, bem como pode se tornar fluido tão logo esteja sob outras condições. Dessa forma, é a melhor definição, pois ela se desvia de toda tentativa de determinação conceitual, escapa às definições e permanece prenhe de possibilidades: "Se entre as diferentes formas que o homem dá a si, elas podem ser diferenciadas, então as formas mais superiores são aquelas que corresponderiam ao seu 'não-ser-determinado', ou seja, formas que deixariam em aberto muitas possibilidades" 52 .

Se o homem também é uma nuance, um pathos conceitualmente indeterminado sem que se possa determinar intencionalmente o que ele se tornará, da mesma forma se deve suspender quaisquer pretensões de o inserir em uma suposta ordenação moral do mundo. Toda ordenação é intencional e carregada de um cortejo de pretensões de melhoramento. Intencionalmente, os imperativos exigem que o homem se torne não o que ele já é, mas um outro que "ele ainda não é" 53 . Na medida em que o homem precisa se desviar de uma moral que pretenda determiná-lo, a fórmula 'tornar-se o que se é' é um paradoxo, pelo menos um paradoxo àqueles que se arrogam o cajado da moralidade e dos bons costumes. Pois 'tornar-se o que se é' não ocorre mais por meios morais, por exemplo, através de uma moral da intencionalidade ${ }^{54}$, mas sim a partir da suspensão de toda moralidade. Tão logo o homem se torne 'moral', ele imediatamente deixa de ser uma nuance e se torna um conceito, ou seja, bom, cristão, sacerdote, etc. Trata-se assim de uma fórmula que não se deixa medir por critérios, configurando-se em uma fórmula imoral destinada àqueles que são "de outra fé" 55 .

\footnotetext{
${ }^{51} \mathrm{EH}$, "O caso Wagner", §4. Cf. Wotling, P. Nietzsche et le problème de la civilasation. Paris: PUF, 1995, especialmente o capítulo em que o autor analisa a fórmula "eu sou uma nuance".

52 TONGEREN, P. v. op. cit., p. 78.

${ }^{53} \mathrm{Cf}$. BABICH, B., op. cit., p. 29s.: "De modo geral, o jardim de variedades em imperativos éticos, morais ou práticos nos exorta a alterar nossas vidas não para nos tornarmos o que (já) somos, mas a partir de possibilidades ideais contrárias às circunstâncias ou fatos imediatos, a idéia é tornarmo-nos o que nós não somos (ainda)." Cf. ainda TONGEREN, Paul v. op. cit., p. 78.

${ }^{54} \mathrm{ABM}, \S 32$.

${ }_{55}$ ABM, §203. Cf. também PfEUfFER, S. Die Entgrenzung der Verantwortung. (Monographien und Texte zur Nietzsche-Forschung). Berlin/New York: Walter de Gruyter, 2008.
} 
Nietzsche atribui a Zaratustra precisamente a tarefa de suspender toda intencionalidade da moral, na medida em que Zaratustra "criou este mais fatal dos erros, a moral”. Porém, continua Nietzsche, "em conseqüência, deve ser também o primeiro a reconhecê-lo", situando a história inteira, neste caso, como "a refutação experimental da sentença da dita 'ordem moral universal”" 56 . Isso é o que distingue Zaratustra, isso é também o que distinguiu Nietzsche, tal como ele escreve, "de toda humanidade" 57 . Não a toa as três últimas sentenças de Ecce homo são perguntas sobre o entendimento daquilo que ele escreveu: "Fui compreendido?”. Não há fórmulas para a fórmula de Nietzsche. Trata-se simplesmente de reconhecer na fórmula a suspensão de toda moralidade; um reconhecimento no qual não há qualquer condenação, mas, simultaneamente, nenhuma absolvição: o que corresponde ao homem é 'tornar-se', mas continuamente indeterminado: "Em outra passagem", escreve Nietzsche sobre Zaratustra, "ele define com o rigor possível o que para ele pode ser somente 'o homem': [...] o homem é para ele algo informe, um material, uma pedra feia que necessita de escultor". ${ }^{58}$

[3] Wie man wird. Resta-nos agora, então, abordar o 'como' alguém se torna. A partícula 'como' é capciosa, pois obviamente não há resposta, pelo menos do ponto de vista da prescrição. Além disso, o 'como’ da fórmula está também estreitamente vinculado à indeterminação do homem, ao homem como o animal 'ainda não determinado', ou como falou Zaratustra, "algo informe”. É preciso acrescentar à partícula, porém, uma hipótese que se ajusta ao destino da tarefa de 'tornar-se o que se é', vale dizer, o pensamento da fluidez. ${ }^{59}$

Diga-se de antemão que a fórmula 'tornar-se o que se é' deve ser tomada como um signo, uma 'mera semiótica'. Trata-se de uma fórmula que Nietzsche emprega através de signos, para exprimir um pensamento que é

\footnotetext{
${ }^{56} \mathrm{EH}$, "Por que sou um destino", §3.

${ }^{57} \mathrm{Cf}$. $\mathrm{EH}$, "Por que sou um destino". No aforismo 6 e 7 desse capítulo, Nietzsche se refere àquilo que 0 "distingue de toda a humanidade", vale dizer, ter escolhido para si a palavra "imoralista" e "haver descoberto a moral cristã". No aforismo 8, reconhece a si mesmo como um "destino" precisamente por ter 'descoberto', como 'imoralista', o erro dos erros: a moral.

${ }^{58} \mathrm{EH}$, "Assim falou Zaratustra", §8.

${ }^{59}$ Sobre essa noção, cf. Stegmaler, W. Philosophie der Fluktuanz: Dilthey und Nietzsche. Göttingen: Vandenhoeck \& Ruprecht, 1992.
} 
essencialmente fluido. Como animal não determinado, o homem só pode estar inserido no signo da fluidez. Isso é possível somente depois que compreendemos o projeto crítico de inversão da compreensibilidade - tal como registrado na nota 16 deste texto -, bem como nossa insistência em relação ao distanciamento da compreensão conceitual da existência. Para além da univocidade conceitual, Nietzsche relega o emprego dos signos ao seu contexto individual de uso, retirando sua validade universal. Assim, 'como' alguém se torna o que é se desdobra na vida de maneira essencialmente prática e, sobretudo, fluida. Fluido é algo que está inteiramente aberto para receber qualquer forma. $\mathrm{O}$ conceito homem, por exemplo, tem uma certa significação. Tão logo mudemos as condições em que empregamos esta noção, muda-se também o próprio sentido de homem. Sob circunstâncias diferentes, um mesmo conceito recebe continuamente um novo significado, sendo impossível fechá-lo em uma definição unívoca. Neste aspecto, a fluidez de um conceito também é uma nuance, de modo a resguardar o caráter de abertura para outras tantas significações. O essencial, porém, é perceber que se a forma homem "é fluida, o 'sentido' é mais ainda", de modo que "toda a história de uma 'coisa', um órgão, um uso, pode desse modo ser uma ininterrupta cadeia de signos de sempre novas interpretações e ajustes." 60

Assim, a partícula 'como' alguém 'se torna' algo não remonta mais a uma definição conceitual, mas é exclusivamente fluida e, portanto, essencialmente prática. Trata-se de um pensamento que zomba "de toda formulação por conceitos" 61 . Um "pensamento" como o de Nietzsche, que é "apenas um signo" 62 , bem como tudo o que se insere em uma semiótica, furta-se a qualquer definição, revelando-se como algo, escreve Nietzsche, "inteiramente indefinível (...): todos os conceitos em que um processo inteiro se condensa semioticamente se subtraem à definição; definível é apenas aquilo que não tem história" 63 . História, porém, é o que mais tem o homem. Compreender o 'como' alguém 'se torna' no sentido de sua fluidez é

\footnotetext{
60 GM II, §12.

${ }^{61}$ ABM, §188.

${ }^{62} \mathrm{Cf}$ KSA 9, 6[253] p. 263: "O pensamento é, da mesma forma que a palavra, apenas um signo, de que não pode estar em questão qualquer correspondência do pensamento com o real. O real é algum tipo de movimento de impulsos."

${ }^{63}$ GM II, §13. Cf. também Stegmaier, W. Schicksal Nietzsches?, p. 70s.
} 
precisamente privilegiar um processo que se desdobra na própria vida, é privilegiar um processo pathetico, é conferir ao 'tornar-se' uma prerrogativa sobre a fixidez do conceito. ${ }^{64}$

'Como' alguém 'se torna' é um processo prático, ou antes, uma “meta prática” 65 . No livro V d'A Gaia Ciência, Nietzsche escreve um aforismo intitulado "Por que não somos idealistas". Logo no início do texto, ele se refere ao contra-conceito de idealista, ou seja, sensualista. Neste caso, se somos todos "sensualistas", não o somos, porém, do ponto de vista conceitual: como sensualistas, há um distanciamento em relação à compreensão conceitual da existência. Somos sensualistas, no fundo, continua Nietzsche, "não conforme a teoria, mas na prática, praticamente" 66 . Trata-se de uma prática sem teoria, ou antes, um conceito para uma práxis que não possui nenhuma teoria ${ }^{67}$. Toda ação, neste caso, ocorre patheticamente e sem o guia de nenhuma intencionalidade, na medida em que sua práxis não pergunta mais por fundamentos e nem se deixa mais conceitualizar. A própria moralidade também se suspende em uma tal prática não-conceitual, sobretudo se suspende aquela moralidade que interpreta "a origem de uma ação a partir de uma intenção”. Nietzsche escreve, porém, que para "nós, imoralistas, corre a suspeita de que o valor decisivo de uma ação está justamente naquilo que nela é não-intencional, e que a sua intencionalidade, tudo o que dela pode ser visto, sabido, 'tornado consciente', pertence ainda à superfície, à sua pele" 68 . Uma ação possui um valor, somente na medida em que alguém a interpreta de determinada forma, portanto, é um valor inserido sub-repticiamente. Em si mesma, porém, elas não são nada ${ }^{69}$. No fundo, escreve Nietzsche, toda "intenção consciente" é meramente um "sintoma" e uma interpretação, na medida em que toda práxis não pergunta mais pelas intenções ou por fundamentos, mas reconhece, ao contrário, que "há inúmeras intencionalidades

\footnotetext{
${ }^{64} \mathrm{Cf}$. BABICH, B. op. cit., p. 47: "Imprimir o 'tornar' na imagem do ser não é para convertê-lo em ser, mas antes para conferir uma superioridade ao 'tornar' (...): Devir no fluxo do acontecimento".

65 KSA 10, 16[11] p. 501.

$66 \mathrm{GC}, \S 372$.

${ }^{67}$ Cf. Stegmaier, W. "Philosophischer Idealismus" und die "Musik des Lebens: zu Nietzsches Umgang mit Paradoxien". In Nietzsche-Studien 33 (2004), p. 90-128, aqui na p. 100ss. Para o autor, o tipo Jesus seria o exemplo de uma prática sem teoria, uma 'praxis evangélica' e uma existência "totalmente imersa em símbolos e incompreensibilidades".

${ }^{68} \mathrm{ABM}, \S 32$.

${ }^{69}$ Cf. A 119. Cf. também A, §116.
} 
inconscientes"70. Assim considerada, "prática deveria então ser compreendida como uma ação em que o agente se tornou de tal modo evidente, de tal modo 'transformado em carne e sangue', que ele não pergunta mais em absoluto por fundamentos; caso fosse questionado por outros em relação aos fundamentos, na medida em que sua ação desconcerta, ele se tornaria incompreensível."71

Cada ação, cada vivência humana, neste caso, não precisa mais de uma interposição conceitual entre o homem e o mundo, de modo que a todo instante alguém estivesse legitimando suas ações. Sem teoria, a prática de uma vivência deve remontar às "condições de vida nas quais elas estão inseridas" e, sob tais circunstâncias, tal ação terá um determinado significado. Tão logo, porém, essas condições se modifiquem, a mesma vivência terá seu sentido deslocado e receberá um novo sentido, revelando o caráter de fluidez de uma tal 'prática': a “intencionalidade da ação não é nada decisivo (...), mas apenas sintomática, em si mesmo ambígua e bem pouco sistematizável”72. Para além da intermediação conceitual entre homem e mundo, 'como' alguém 'se torna' algo não é mais medido por critérios, mas sim dependerá sempre das condições de vida que alguém pratica algo. Em suma, o 'como' da fórmula é uma prática sem teoria e, portanto, registrada sob o signo da fluidez.

Em suma, destino e fluidez são as duas palavras-chave para interpretar a suspensão da intencionalidade na fórmula 'tornar-se o que se é'. O homem é algo que deve sempre ser pensado para além dele e nunca reduzido a uma formulação conceitual. A fórmula é antes um contra-conceito àquilo que "hoje" se ouve dizer: "assim e assim deveria ser o homem", pois isso soa como "ironia" àqueles que não precisam mais de artigos de fé extremados. Para além dos imperativos extremados, Nietzsche simplesmente evoca que, "apesar de tudo", é preciso "apenas se tornar, o que se ê"73. O 'destino da tarefa' é uma práxis sem teoria, cujo agente não pergunta mais por fundamentos e, além disso, não tem nenhum saber prévio sobre aquilo que ele é, a fim de realizar, posteriormente, tal saber-de-si no vir-a-ser. A tarefa simplesmente se impõe, impõe-se patheticamente como destino, em que se parte de um não-saber para apenas 'tornar-se' algo que nunca estará

\footnotetext{
70 KSA 12, 1[76] p. 29.

${ }^{71}$ Stegmaier, W. "Philosophischer Idealismus" und die "Musik des Lebens", p. 101.

72 KSA 11, 40[54] p. 655.

${ }^{73}$ KSA 13, 14[113] p. 290.
} 
determinado, e sem que também se saiba, de antemão, o que se tornará. A fórmula evoca apenas uma prática que se desdobra no pathos próprio da vida. Como tal, ela é uma tarefa que se impõe como destino - contraconceito da intencionalidade -, mas também é uma fórmula que implica em fluidez ao homem - pois é uma prática para uma práxis sem teoria. Se há algum 'querer' intencional na trajetória de 'tornar-se o que se é', seria unicamente aquele que o próprio Nietzsche registra na epígrafe de Ecce homo, vale dizer, um gesto de agradecimento, um querer ter sido agradecido: "Como não deveria ser grato à minha vida inteira?". 


\section{Referências}

BABICH, B. "Nietzsche's Imperative as a Friend's Encomium: on becoming the one you are, ethics, and blessing”. In Nietzsche-Studien 32(2003), p. 29-58.

Cramer, K. "Erleben, Erlebnis”. In RitTeR, Joachim (Hrsg.) Historisches Wörterbuch der Philosophie. Band 2: D-F. Basel/Stuttgart: Schwabe \& Co. Verlag, 1972.

GADAMER, H-G. Wahrheit und Methode: Grundzüge einer philosophischen Hermeneutik. Tübingen: J.C.B. Mohr, 1990.

GERHARDT, v. Pathos und Distanz. Stuttgart: Reclam, 1988.

Kornberger, M. "Zur Genealogie des 'Ecce homo”. In Nietzsche-Studien 27(1998), p. 319-338.

Montinari, M. "Ein neuer Abschnitt in Nietzsches Ecce homo". In NietzscheStudien 1(1972), p. 380-418.

Nehamas, A. Nietzsche: la vida como literatura. México: Fondo de Cultura Econômica, 2002.

NIETZSCHE, F. Kritische Studienausgabe in 15 Bänden. (KSA) Hrsg. Giorgio Colli und Mazzino Montinari. Berlin/New York: DTV \& Walter de Gruyter, 1980.

- Humano, demasiado Humano. Trad. Paulo César de Souza. São Paulo: Companhia das Letras, 2000.

Aurora. Trad. Paulo César de Souza. São Paulo: Companhia das Letras, 2004. A Gaia Ciência. Trad. Paulo César de Souza. São Paulo: Companhia das Letras, 2001.

Assim falou Zaratustra: um livro para todos e para ninguém. Trad. Mario da Silva. Rio de Janeiro: Bertrand Brasil, 1998.

. Além do bem e do mal. Trad. Paulo César de Souza. São Paulo: Companhia das Letras, 1998.

Genealogia da moral. Trad. Paulo César de Souza. São Paulo: Companhia das Letras, 1998.

. Crepúsculo dos ídolos. Trad. Paulo César de Souza. São Paulo: Companhia das Letras, 2006.

. Ecce Homo. Trad. Paulo César de Souza. São Paulo: Companhia das Letras, 2004.

OtTMAnN, H. (Hrsg.) Nietzsche: Leben-Werk-Wirkung. Stuttgart-Weimar: J.B. Metzler Verlag, 2000.

PfeufFer, S. Die Entgrenzung der Verantwortung. (Monographien und Texte zur Nietzsche-Forschung). Berlin/New York: Walter de Gruyter, 2008. 
SCHANK, G. Dionysos gegen den Gekreuzigten: eine philologische und philosophische Studie zu Nietzsches "Ecce homo". Bern/Berlin: Europäischer Verlag der Wissenschaften, 1993.

StegmaieR, w. Philosophie der Fluktuanz: Dilthey und Nietzsche. Göttingen: Vandenhoeck \& Ruprecht, 1992.

"Nietzsches Kritik der Vernunft seines Lebens: Zur Deutung von 'Der Antichrist' und 'Ecce Homo'”. In Nietzsche-Studien 21 (1992), p. 163-183.

. Nietzsches Zeichen. In Nietzsche-Studien 29 (2000), p. 41-69.

"Anti-Lehren: Szene und Lehre in Nietzsches Also Sprach Zarathustra". In

GERHARDT, V. (Hg.), Klassiker auslegen: Friedrich Nietzsche: Also Sprach Zarathustra, Berlin: Akademie Verlag, 2000.

"Philosophischer Idealismus und die Musik des Lebens: zu Nietzsches Umgang mit Paradoxien”. In Nietzsche-Studien 33 (2004), p. 90-128.

. "Schicksal Nietzsche? Zu Nietzsches Selbsteinschätzung als Schicksal der

Philosophie und der Menschheit”. In Nietzsche-Studien 37 (2008), p. 62-114.

SteInmann, M. Die Ethik Friedrich Nietzsches. (Monographien und Texte zur Nietzsche-Forschung). Berlin/New York: Walter de Gruyter, 2000.

Tongeren, P. van. Die Moral von Nietzsches Moralkritik. Studie zu "Jenseits von Gut und Böse”. Bonn: Bouvier, 1989.

VISSER, G. "Nietzsches Übermensch: die Notwendigkeit einer Neubesinnung auf die Frage nach dem Menschen”. In Nietzsche-Studien 28(1999), p. 100-124.

Erlebnisdruck: Philosophie und Kunst im Bereich eines Übergangs und Untergangs. Würzburg: Königshausen und Neumann, 2005.

WotLING, Patrick. Nietzsche et le problème de la civilasation. Paris: PUF, 1995. 